\title{
Spatial Variability of Soil Phosphorus and Potassium and Its Influencing Factors in the Fragile Red Beds Ecosystem in Southern China
}

\author{
Ping Yan ${ }^{1}$, Kairong Lin ${ }^{1,2,3 *}$, Chenxi Yu${ }^{4}$, Xinjun Tu${ }^{1}$ \\ ${ }^{1}$ School of Civil Engineering, Sun Yat-sen University, Guangzhou, China \\ ${ }^{2}$ Guangdong Key Laboratory of Oceanic Civil Engineering, Guangzhou, China \\ ${ }^{3}$ Southern Marine Science and Engineering Guangdong Laboratory, Zhuhai, China \\ ${ }^{4}$ CAS Key Laboratory of Tropical Marine Bio-resources and Ecology, Guangdong Provincial Key Laboratory of Applied \\ Marine Biology, South China Sea Institute of Oceanology, Chinese Academy of Sciences, Guangzhou, China
}

Received: 31 December 2020

Accepted: 15 April 2021

\begin{abstract}
Soil phosphorus $(\mathrm{P})$ and potassium $(\mathrm{K})$ nutrients are the basis of maintaining the ecosystem function of red beds landform area. Topography is one of the main influencing factors of soil $\mathrm{P}$ and $\mathrm{K}$ nutrients contents. This study focuses on the soil of typical red beds landform in southern China. The semi variogram model of soil $\mathrm{P}$ and $\mathrm{K}$ nutrients was established by geostatistics and GIS technology. Moran's I coefficient was used to analyze the spatial autocorrelation of soil $\mathrm{P}$ and $\mathrm{K}$ nutrients. The spatial distribution characteristics of soil $\mathrm{P}$ and $\mathrm{K}$ nutrients were studied by the interpolation method, and the correlations between soil P, K nutrients and terrain factors (elevation, slope and aspect) were discussed. The results showed that: (1) the soil total phosphorus (TP) content was relatively high, the soil available potassium (AK) content was at a medium level, the soil TP and soil available phosphorus (AP) content were relatively low, and the variation coefficient in decreasing order was AP (36.39\%)>AK (28.43\%)> TP (28.23\%)>total potassium (TK) $(24.33 \%)$. (2) The content of soil P and K in the southwest of the study area was higher than other areas, the lowest value in the grassland and the middle value in the red bed bare land. (3) The soil TP, TK, AP, AK showed strong spatial autocorrelation, Moran's I coefficients of soil $\mathrm{P}$ and $\mathrm{K}$ were all positive, following spatial agglomeration distribution. Moran's I coefficients in decreasing order was AK (0.2174)>TP (0.2000)>AP (0.1897)>TK (0.1665), respectively. (4) The correlation analysis of soil $\mathrm{P}, \mathrm{K}$ nutrients and terrain factors showed that soil TP, TK, AP, AK nutrients and terrain factors (elevation, aspect) had extremely significant positive correlations $(P<0.01)$, in particular, soil AK has a significant positive correlation with elevation
\end{abstract}

*e-mail: linkr@mail.sysu.edu.cn 
$(P<0.01)$, and the correlation coefficient is 0.901 . The results are of great practical significance to soil management and ecological environment management in the red bed area.

Keywords: red bed soil, spatial variability, soil phosphorus, soil potassium, influencing factors

\section{Introduction}

Soil is a natural integration with complex morphology and evolution process. It is affected by soil-forming factors such as climate, biology, parent material, topography and soil-forming time, which has complexity and spatial-temporal variability [1-3]. Even in the areas with the same soil type and texture, there are significant spatial differences in soil properties [4, 5]. Soil phosphorus $(\mathrm{P})$ and potassium $(\mathrm{K})$ nutrients are essential nutrients for plant growth, which are basic materials of soil fertility and important indicators of land management [6]. Due to the co-action of natural factors and human activities, soil $\mathrm{P}$ and $\mathrm{K}$ nutrients have high spatial variability [7]. Soil $\mathrm{P}$ and $\mathrm{K}$ nutrients are not only necessary nutrients for plant growth and development, but also important attributes affecting regional agricultural ecological environment $[8,9]$.

The contents of soil $\mathrm{P}$ and $\mathrm{K}$ are different at different spatial locations, and have general differences in different ecological environments. Studying the spatiotemporal variation mechanism of soil phosphorus and potassium under the driving forces of climate, topography and human activities is one of the most discussed topics in the field of soil science [10]. Therefore, systematical understanding of soil $\mathrm{P}$ and $\mathrm{K}$ content levels and spatial distribution characteristics is necessary for evaluating soil nutrients productivity, predicting and controlling potential environmental pollution, and understanding climate change [11] and its environmental effects.

With the development of computer science, the combination of geostatistics and geographic information technology (GIS) technology has become one of the most used methods to study the spatial variability of soil properties [12]. Since the late 1970s, researchers have applied geostatistics to the spatial variability of soil properties [13-15]. For example, Sanjib et al. analyzed the spatial variability of soil properties in a hot and humid tropical region of southern India [16]. Gwak et al. analyzed the influencing factors of spatial variability of soil moisture in woodland hillside environment [17]. Motaggian et al. used geostatistical analysis to study the spatial variability of soil aggregation stability in a semi-arid area of central Iran [18]. In China, the research topics of spatial variability related to soil properties have involved various ecosystems, including the loess plateau region [19, 20], the southwest karst region [9, 21], the northwest arid region [22], the sandy land [23], the northeast black soil region [24]. However, there are few reports on the spatial variability of soil nutrients in red beds areas in southern China.
Red beds consist of a list of complex strata including conglomerate, glutenite, sandstone, siltstone, and argillaceous rock [18]. The red beds themselves have strong water permeability, and the development of soil layer is relatively difficult, resulting in poor red beds soil and serious degradation $[25,26]$. In the red beds geomorphic region of south China, excessive land use has existed for a long time. Due to the effect of human activities, the original ecological structure of the soil surface has been destroyed. Under the comprehensive action of various external forces, the soil layer is rapidly eroded, and the red beds rock or its weathering crust is exposed, presenting a red desert landscape [27]. Extreme land degradation is caused by land productivity depletion. At the same time, soil nutrients are also lost with land degradation, and the ecological environment is extremely fragile [28]. At present, due to the limit of space, time, manpower and material resources, the soil properties in red beds ecologically vulnerable areas have not been reported. In addition, it is not clear whether the geostatistics analysis method is suitable for analyzing the soil spatial variability in red beds ecologically vulnerable areas. The spatial distribution pattern of soil $\mathrm{P}$ and $\mathrm{K}$ in the red beds ecologically fragile area of southern China is not clear, and the relations between them and the related environmental factors needs to be further studied.

In view of these facts, this study used geostatistics to study the spatial distribution characteristics of soil $\mathrm{P}$ and $\mathrm{K}$ nutrients in red beds landform area of southern China based on the field investigation and laboratory test analysis. The spatial heterogeneity of soil nutrients in red beds and its relation with topography and geomorphology were discussed. The results of this study not only help to deepen the understanding of soil development patterns, but also reveal the relationship between the spatial pattern of red beds ecosystem and ecological processes and functions. The main objectives of this study are: (1) to clarify the spatial variability of soil $\mathrm{P}$ and $\mathrm{K}$ nutrients; (2) to analyze the spatial distribution of soil $\mathrm{P}$ and $\mathrm{K}$ nutrients; and, (3) to explore the interaction mechanism between the spatial variability of soil $\mathrm{P}$ and $\mathrm{K}$ nutrients and topographic factors.

\section{Materials and Methods}

\section{Study Area}

Nanxiong basin is a fault basin controlled by the Nanxiong fault along the northern margin with an area of $1800 \mathrm{~km}^{2}$ spanning Guangdong and Jiangxi provinces 
$\left(24^{\circ} 56^{\prime} 59^{\prime \prime} \sim 25^{\circ} 25^{\prime} 20^{\prime \prime} \mathrm{N}, 113^{\circ} 55^{\prime} 30^{\prime \prime} \sim 114^{\circ} 44^{\prime} 38^{\prime \prime} \mathrm{E}\right)$ (Fig. 1). The length of the basin is $80 \mathrm{~km}$ from west to east, and the width is more than $30 \mathrm{~km}$ from south to north. The region belongs to the subtropical monsoon humid climate zone, with four distinct seasons, short winter and long summer, and fast transition in autumn. The annual average temperature is $19.6^{\circ} \mathrm{C}$, the annual average evaporation is $1678.7 \mathrm{~mm}$, the annual average rainfall is $1555.1 \mathrm{~mm}$, and the total rainfall is abundant. There are four types of natural soil: yellow soil, red soil, red lime soil and purple soil. The soil in the study area is mainly alkaline purple soil. The main vegetation communities are Pinus massoniana mixed with broadleaved trees, deciduous trees and broad-leaved trees mixed secondary forest, eucalyptus forest, pine forest and so on. Land use patterns mainly include farmland, forestland and grassland $[25,28]$.

\section{Field Sampling}

The soil sampling was conducted in the northeast of Nanxiong basin as a long-term monitoring sample site in November 2017 (Fig. 1). Soil sampling points were arranged by uniform grid method covering the whole study area. The locations of sampling points were measured using GPS. A total of 225 sampling points were set up based on the forest status, vegetation and terrain distribution of Nanxiong basin. The interval

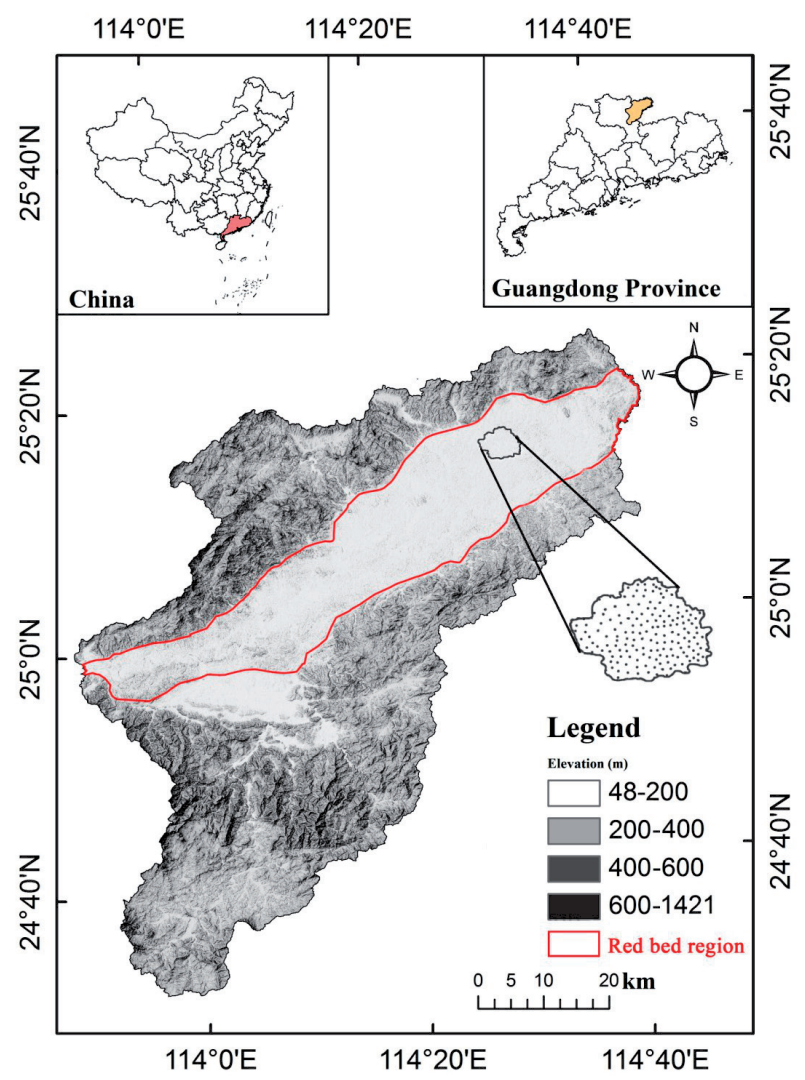

Fig.1. Location of the study area and distribution of soil sampling sites [25, 28]. between each sampling point ranged from $50 \mathrm{~m}$ to $300 \mathrm{~m}$. The sampling depth is $0-20 \mathrm{~cm}$. At each sampling point, 3-7 soil samples are taken from the center of the field and its surrounding radius of $10-20 \mathrm{~m}$ according to the "s" shape. Then, $1 \mathrm{~kg}$ is reserved as the soil sample in the quartering method after uniform mixing [20, 28]. The slope, aspect, altitude, soil thickness and other related site factors were also recorded. All mixed soil samples were taken back to the laboratory for air drying and sieving, and then the dried soil samples were used to determine and analyze the soil chemical properties (TP, TK, AP, AK).

\section{Laboratory Testing}

Soil total $\mathrm{P}$ was determined by alkaline digestion followed by molybdate colorimetric measurement [29]. Total K was determined by digesting in sodium hydroxide and then measured by atomic absorption spectrometer [24]. Soil available K was measured by atomic absorption spectrometer [30]. And soil available $\mathrm{P}$ was detected by spectrophotometry and flame photometry [11].

\section{Data Analysis}

The basic characteristics of soil $\mathrm{P}$ and $\mathrm{K}$ nutrients were estimated by calculating the mean value, variance, coefficient of variation, kurtosis and skewness of the original data. In addition, to use the original soil data in descriptive statistics, the transformed data meeting the normal distribution were used in the rest of the statistical process, and the Shapiro Wilk method was used to test the normality. The relationship between soil $\mathrm{P}$ and $\mathrm{K}$ nutrients and terrain factors was studied using the partial correlation analysis. The sample data was also analyzed and processed using classical statistics and geostatistics methods supported by SPSS 18.0 (Statistical analysis and test, Pearson correlation), GS+7.0 (Geostatistical analysis), ArcGIS 10.5 (Kriging interpolation map).

\section{Semivariogram Analysis}

The semivariance analysis and spatial autocorrelation analysis based on Moran's I coefficient were used to study the spatial variation characteristics of soil, which were completed in GS +7.0 software. Semivariance analysis is commonly used to study the spatial variation of factors in geostatistics [31]. In particular, it used to express the spatial dependence of regional variables, and it can accurately summarize the variation characteristics using a function fitting method [32]. The formula is as follows:

$$
\gamma(h)=\frac{1}{2 N(h)} \sum_{i=1}^{N(h)}\left[Z\left(x_{i}\right)-Z\left(x_{i}+h\right)\right]^{2}
$$


Where, $\gamma(\mathrm{h})$ is the semivariogram of lag distance $h$, $N$ (h) is the number of sample pairs separated from $\mathrm{h}$, and $\mathrm{Zi}$ and $\mathrm{Zi}+\mathrm{h}$ are the measured values of $\mathrm{Z}$ at position $i$ and $i+h$, respectively. Nugget value $\left(C_{0}\right)$, abutment value $\left(\mathrm{C}_{0}+\mathrm{C}\right)$ and range $(\mathrm{A})$ are important parameters in semivariance analysis. The nugget value $\mathrm{C}_{0}$ represents the variation degree of variables when the lag distance is very small, and the range (A) represents the sample spacing when the semivariance reaches the base value, which is used to measure the range of spatial autocorrelation. The base value is the corresponding value when the half-square difference reaches a stable value with the increase of lag distance, which is the embodiment of the overall characteristics of regionalized variables. The block basis ratio is used to represent the degree of spatial variability. If the ratio is less than $25 \%$, it means that the variables have strong spatial autocorrelation, and if the ratio is between $25 \%$ and $75 \%$, the variables have moderate spatial autocorrelation. When the ratio is greater than $75 \%$, the variables have weak spatial autocorrelation [33].

\section{Spatial Autocorrelation Analysis}

In addition, spatial autocorrelation analysis based on Moran's I coefficient was used to explore the scale effect of the spatial distribution of soil factors in further [34]. The Moran's I coefficient is designed to measure the similarity of unit attribute values on adjacent area cells. Its advantage is that it can distinguish the positive autocorrelation from the negative one, and its research scale is different from that of semivariance analysis, which is not limited to half of the maximum sampling interval. The calculation formula is as follows:

$$
I_{i}=\frac{Z_{i}-\bar{Z}}{\sigma^{2}} \sum_{j=1, j \neq}^{n}\left[W_{i j}\left(Z_{i}-\bar{Z}\right)\right]
$$

Where, I (h) is the autocorrelation function of lag distance $h$. In the spatial autocorrelation analysis, Moran's I coefficient greater than 0 indicates positive spatial autocorrelation, which reflects the spatial aggregation of similar attributes in adjacent regions. Moran's I coefficient less than 0 , means negative spatial autocorrelation. The attributes reflects the difference have spatial aggregation in adjacent regions. When the coefficient is equal to 0 , it means that there is no spatial autocorrelation, that is, the variables are randomly distributed in adjacent regions [35].

\section{Results and Discussion}

\section{Descriptive Statistics of Soil P and K Nutrients}

Table 1 displays the descriptive statistical characteristics of soil $\mathrm{P}$ and $\mathrm{K}$ nutrients in the study. As shown in table 1, the content range of soil TP, TK, AP and AK vary within the range of $0.40-2.30 \mathrm{~g} \mathrm{~kg}^{-1}$, $5.50-25.00 \mathrm{~g} \mathrm{~kg}^{-1}, 4.20-20.10 \mathrm{mg} \mathrm{kg}^{-1}, 75.00-210.00 \mathrm{mg} \mathrm{kg}^{-1}$ respectively. The coefficient of variation AP (36.39\%) $>$ AK (28.43 \%)> TP (28.23\%)>TK (24.33\%), indicating that these four indicators have medium variation intensity. The absolute values of skewness and kurtosis were less than 1 , and $P>0.05$ after $\mathrm{K}-\mathrm{S}$ test, which means that the data measured by the above four indicators obey normal distribution.

It is thus clear that the soil TP content is at a high level in the study area while the soil AK content is at a medium level. The variation coefficient of soil AP is relatively large, which indicates that the content of soil AP varies sharply. The main reason is that the abundance and deficiency of soil $\mathrm{P}$ and its distribution are related to the types and quantities of phosphorus minerals in the soil, and they are also affected by the geographical location, soil parent material, soil development degree, soil texture and land utilization mode. In addition, the terrain change in the study area is complex, which leads a sharp variation of AP content.

\section{Spatial Variability of Soil P and K \\ Semivariance Analysis of Spatial Variation of Soil $P$ and $K$ Nutrients}

Sampling interval is the main reason for the difference of range. In this study, the range is the spatial variation range of $\mathrm{P}$ and $\mathrm{K}$ soil nutrients, so it can guide the sampling design to a certain extent. The range of soil $\mathrm{P}$ and $\mathrm{K}$ nutrients in this study ranged from $318.00 \mathrm{~m}$ to $2986.40 \mathrm{~m}$, and the sampling design scale was 50-300 $\mathrm{m}$, which met the requirements of geostatistics

Table 1. Statistical characteristic of soil TP, TK, AP, AK.

\begin{tabular}{|c|c|c|c|c|c|c|c|c|}
\hline $\begin{array}{c}\text { Soil } \\
\text { nutrients }\end{array}$ & Min & Max & Mean & $\begin{array}{c}\text { Standard } \\
\text { deviation }\end{array}$ & Skewness & Kurtosis & $\begin{array}{c}\text { Coefficient of } \\
\text { variation }(\%)\end{array}$ & K S test \\
\hline $\mathrm{TP}\left(\mathrm{g} \mathrm{kg}^{-1}\right)$ & 0.40 & 2.30 & 1.24 & 0.35 & -0.077 & 0.207 & 28.23 & 1.38 \\
\hline $\mathrm{TK}\left(\mathrm{g} \mathrm{kg}^{-1}\right)$ & 5.50 & 25.00 & 15.37 & 3.74 & -0.268 & 0.203 & 24.33 & 1.63 \\
\hline $\mathrm{AP}\left(\mathrm{mg} \mathrm{kg}^{-1}\right)$ & 4.20 & 20.10 & 10.80 & 3.93 & -0.913 & 0.354 & 36.39 & 1.89 \\
\hline $\mathrm{AK}\left(\mathrm{mg} \mathrm{kg}^{-1}\right)$ & 75.00 & 210.00 & 134.19 & 38.16 & -1.470 & 0.211 & 28.43 & 2.66 \\
\hline
\end{tabular}

TP: Total phosphorus; TK: Total potassium; AP: Available phosphorus; AK: Available potassium. 
Table 2. Semivariance model and its parameters for soil TP, TK, AP, AK.

\begin{tabular}{|c|c|c|c|c|c|c|c|}
\hline $\begin{array}{c}\text { Soil } \\
\text { nutrients }\end{array}$ & Theoretical model & $\begin{array}{c}\text { Nugget } \\
\left(\mathrm{C}_{0}\right)\end{array}$ & $\begin{array}{c}\text { Sill } \\
\left(\mathrm{C}_{0}+\mathrm{C}\right)\end{array}$ & $\begin{array}{c}\text { Nugget/Sill } \\
(\%)\end{array}$ & $\begin{array}{c}\text { Range } \\
(\mathrm{m})\end{array}$ & $\begin{array}{c}\text { Determining } \\
\text { coefficient }\end{array}$ & Residual \\
\hline $\mathrm{TP}\left(\mathrm{g} \mathrm{kg}^{-1}\right)$ & Exponential model & 0.02 & 0.13 & 14.17 & 426.00 & 0.42 & 21.15 \\
\hline $\mathrm{TK}\left(\mathrm{g} \mathrm{kg}^{-1}\right)$ & Spherical model & 0.52 & 13.71 & 3.79 & 360.00 & 0.02 & 18.81 \\
\hline $\mathrm{AP}\left(\mathrm{mg} \mathrm{kg}^{-1}\right)$ & Exponential model & 2.21 & 15.41 & 14.34 & 318.00 & 0.27 & 13.70 \\
\hline $\mathrm{AK}\left(\mathrm{mg} \mathrm{kg}^{-1}\right)$ & Linear model & 1333.78 & 1461.97 & 27.72 & 2986.40 & 0.11 & 176142.00 \\
\hline
\end{tabular}

sampling and could reflect the spatial pattern information of soil nutrients. It can be seen from Table 2 that the theoretical models of soil TP, TK, AP and AK are: empirical model, spherical model, empirical model and linear model, and the range from large to small is AK (2986.40)> TP (426.00) $>$ TK (360.00) $>$ AP (318.00), indicating that the spatial autocorrelation distance of $\mathrm{AK}$ is larger, and the autocorrelation distance of AP is smaller, and the spatial autocorrelation intensity is AK (27.72\%)>AP (14.34\%)> TP (14.17\%)>TK (3.79\%).

The spatial variation of soil $\mathrm{P}$ and $\mathrm{K}$ content is affected by soil type, topography, parent material and other factors. The results showed that the soil TP, TK, AP and AK had good spatial structure, and the block to base ratio of AK was $27.72 \%$, which belongs to medium spatial autocorrelation. The block to base ratio of soil TP, TK and AP were all less than $25 \%$, which means the soil TP, TK and AP had strong spatial autocorrelation, indicating that the spatial variability of soil nutrients was mainly caused by structural factors (climate, parent material, topography, soil type), and there were not too many random factors (cultivation, fertilization and other human factors).
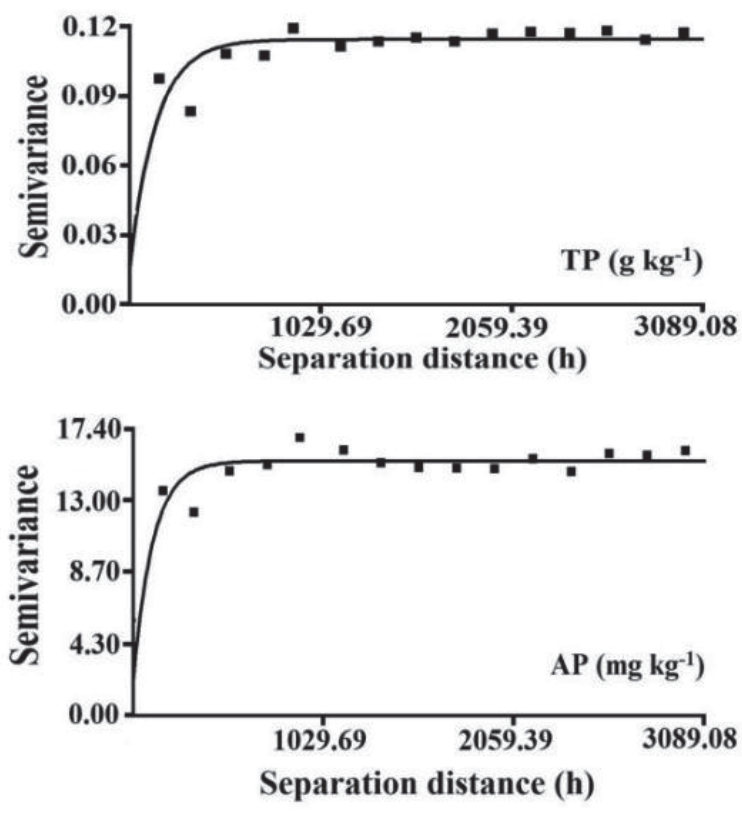

\section{Spatial Autocorrelation Analysis of Soil P and $K$ Nutrients}

The spatial autocorrelation Moran's I coefficient of soil $\mathrm{P}$ and $\mathrm{K}$ was calculated by ArcGIS 10.5. As can be seen from Table $3, \mathrm{Z}$ scores $>1.96$ and $\mathrm{P}$ values $<0.01$, indicating that Moran's I coefficient has passed the test, with a confidence of $99 \%$. The Moran's I coefficient of soil $\mathrm{P}$ and $\mathrm{K}$ nutrients is positive, which indicates that the soil $\mathrm{P}$ and $\mathrm{K}$ nutrients in the study area have positive spatial correlation, which belongs to the spatial concentration distribution. The Moran's I coefficient of the four indicators in decreasing order is AK (0.2174) $>$ TP (0.2000)>AP (0.1897)> TK (0.1665), which means that the spatial agglomeration of AK was strongest, and TK was the weakest.

Fig. 3 shows that the variation of Moran's I coefficient of soil $\mathrm{P}$ and $\mathrm{K}$ nutrients to the interval distance (step length). Within the range of $1029.69 \mathrm{~m}$, Moran's I coefficient of soil $\mathrm{P}$ and $\mathrm{K}$ nutrients first increases and then decreases with the interval distance analyzed, indicating that soil $\mathrm{P}$ and $\mathrm{K}$ nutrients have a certain effect on the distribution of soil $\mathrm{P}$ and $\mathrm{K}$ nutrients. The distance of positive correlation roughly
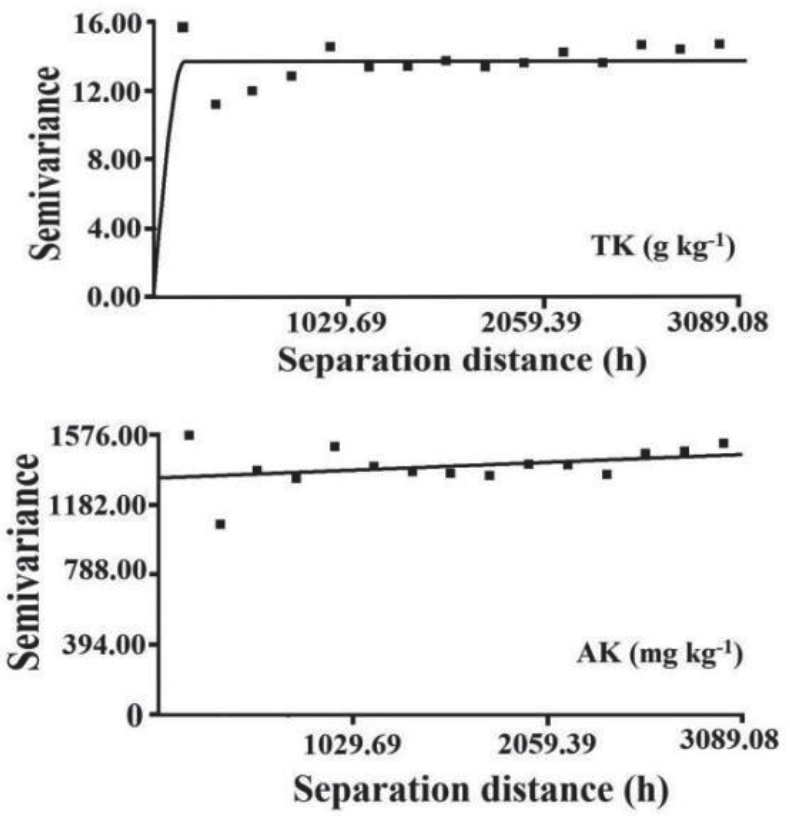

Fig. 2. Semivariograms and fitted model of soil TP, TK, AP, AK. 
Table 3. Moran's I coefficient of soil TP, TK, AP, AK.

\begin{tabular}{|c|c|c|c|}
\hline Soil nutrients & Moran's I & $\mathrm{Z}$ & $\mathrm{P}$ \\
\hline $\mathrm{TP}\left(\mathrm{g} \mathrm{kg}^{-1}\right)$ & 0.2000 & 4.8485 & 0.000001 \\
\hline $\mathrm{TK}\left(\mathrm{g} \mathrm{kg}^{-1}\right)$ & 0.1665 & 4.0542 & 0.000050 \\
\hline $\mathrm{AP}\left(\mathrm{mg} \mathrm{kg}^{-1}\right)$ & 0.1897 & 4.5966 & 0.000004 \\
\hline $\mathrm{AK}\left(\mathrm{g} \mathrm{kg}^{-1}\right)$ & 0.2174 & 5.2442 & 0.000000 \\
\hline
\end{tabular}

reflects the average radius of patches with similar properties. It can be seen from Fig. 3 that the soil phosphorus and potassium nutrients in the study area present a certain structure, and there are similar spatial structures between soil TP and AP, TK and AK. The spatial positive correlation between soil TP and AP, when the step size is smaller than $915.28 \mathrm{~m}$ can be obtained. The positive correlation scale of soil TP is 915.28m. Soil TK and AK also showed a positive spatial correlation in the step size of $1029.69-2402.61 \mathrm{~m}$. This result may be due to the high absorption efficiency of phosphorus and potassium for beings nutrient elements of plants.

\section{Spatial Distribution of Soil P and K Nutrients}

Based on the calculation results of the soil $\mathrm{P}$ and $\mathrm{K}$ nutrients variogram model, the kriging method in the geostatistics module of ArcGIS 10.5 was used to draw the contour map of spatial distribution of soil $\mathrm{P}$ and $\mathrm{K}$ nutrients (Fig. 4). As shown in Fig. 4, soil $\mathrm{P}$ and $\mathrm{K}$ nutrients contents have obvious spatial heterogeneity and good spatial continuity. The similarity of spatial distribution is consistent with the partial correlation coefficient of soil physical and chemical properties in partial correlation analysis, which indicates that the spatial distribution of soil $\mathrm{P}$ and $\mathrm{K}$ characteristics has correlations, and the synergistic relationship needs to be further studied. In general, the content of soil $\mathrm{P}$ and $\mathrm{K}$ in the southeast of the study area was higher than that in other areas, and the content of soil TP in the south of the study area was significantly higher than that in the north. The lowest value was mainly distributed in the northwest of the study area. The content of soil TK in the southwest was significantly higher than that in other areas. The distribution of soil AP content was spotted, and different contents were concentrated in closed small areas. The soil AK decreased from northwest of the study area to middle (grassland and red bed bare land) then increased to the southwest (forest). This is mainly related to the content of organic matter in the soil. The accumulation and decomposition of soil organic matter can directly affect the storage and transformation of phosphorus and potassium, and the mineralization of organic matter can release phosphorus and potassium. The decomposition of plant litter under the forest increases the soil nutrients. Because of the high content of organic matter in soil, the content of soil $\mathrm{P}$ and $\mathrm{K}$ in forest land is relatively higher than that in grassland and bare land.

Further analysis in Fig.4 shows that the areas where soil $\mathrm{P}$ and $\mathrm{K}$ nutrients are lost are generally located at the large hillsides left by several villages. This indicates that terrain is the premise of soil $\mathrm{P}$ and $\mathrm{K}$ accumulation and distribution, and it is closely related to human activities. In the study area, the loss of soil $\mathrm{P}$ and $\mathrm{K}$ nutrients in Tangxia village, Kongkeng village, Huangtuling village and Piankeng village is not obvious. The original vegetation communities in this area have disappeared. Most of them are Pinus massoniana, Pinus elliottii and Cunninghamia lanceolata, which are planted artificially in the early stage. Most of them are distributed in large areas close
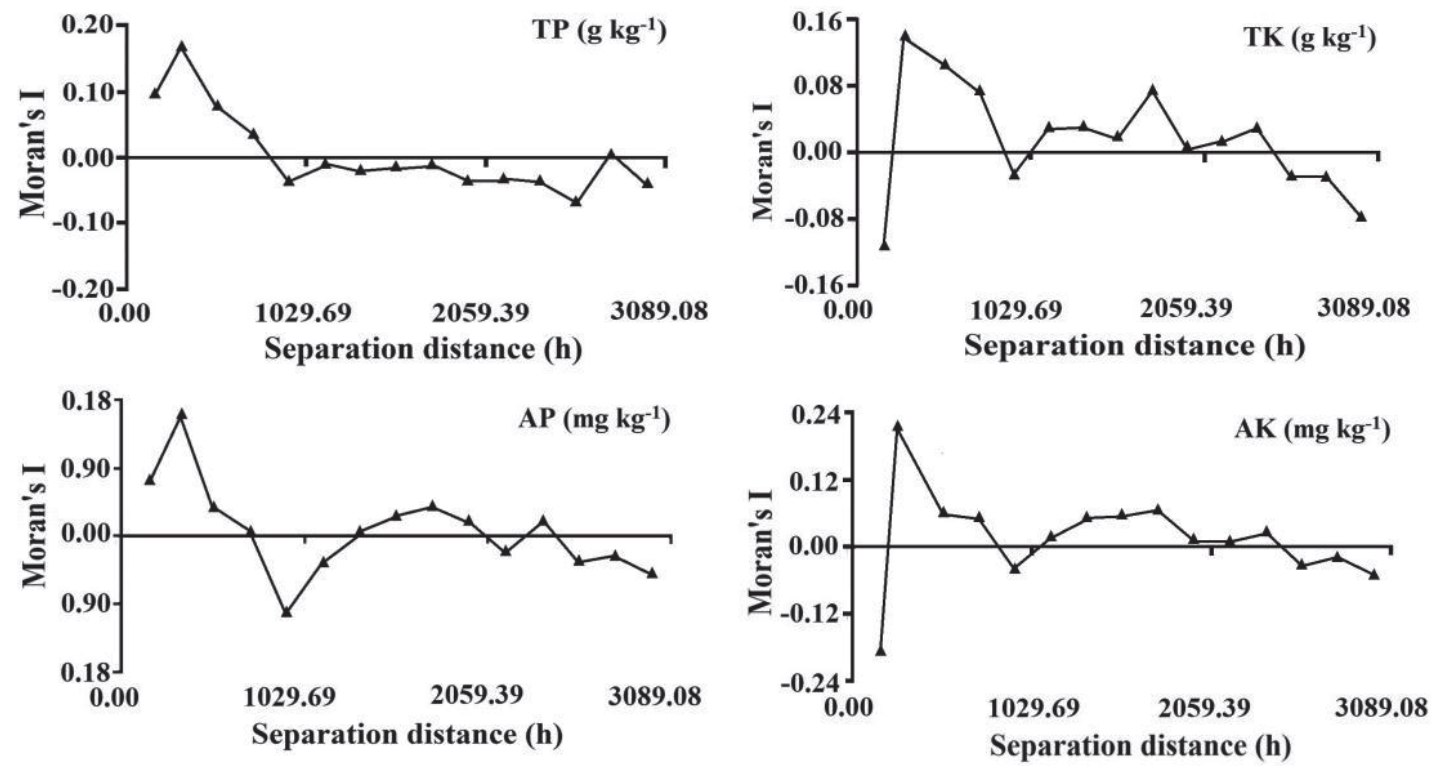

Fig. 3. Spatial intercorrelograms of soil TP, TK, AP, AK. 

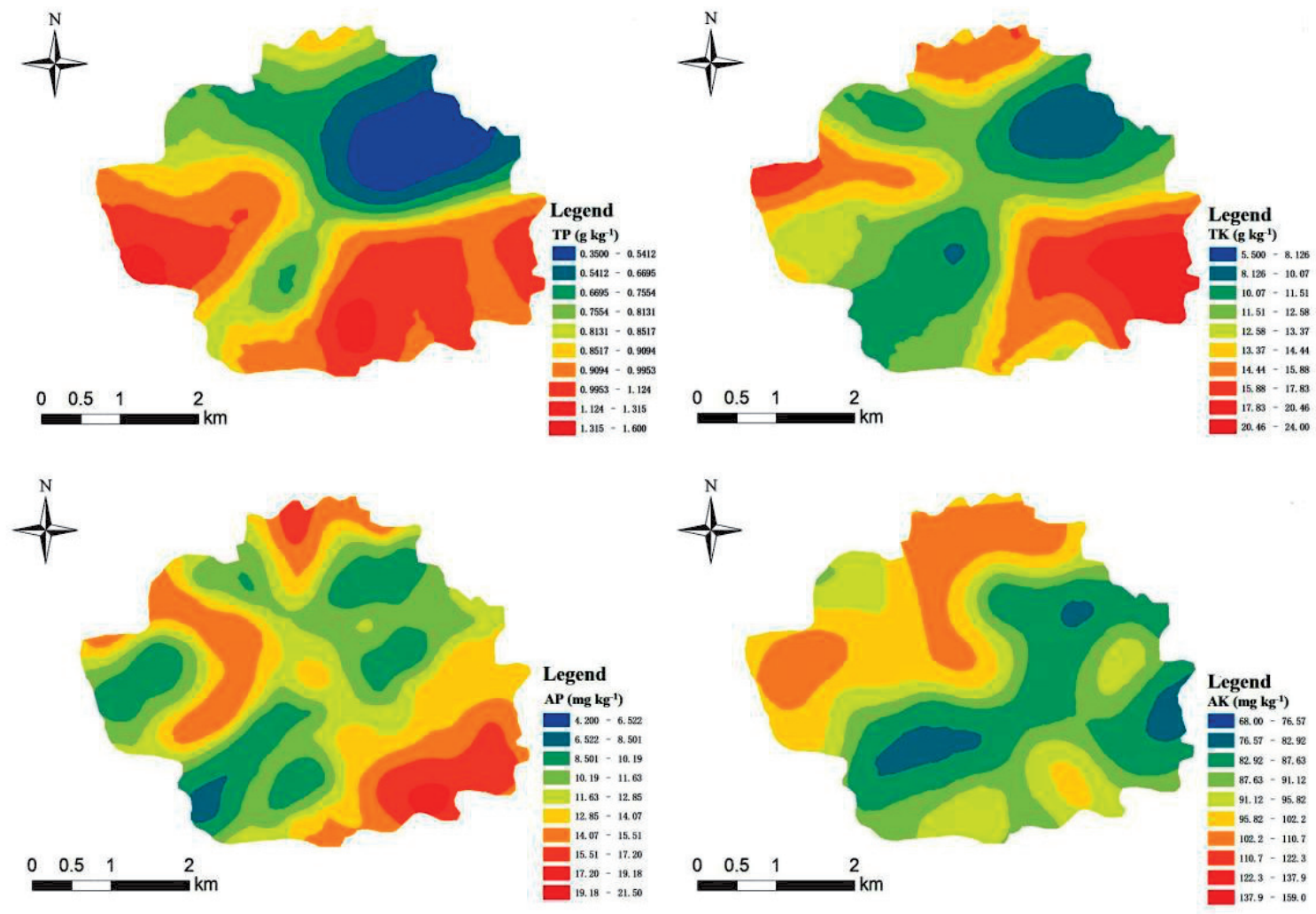

Fig. 4. Kriging interpolation map of soil TP, TK, AP, AK.

to villages. The conditions of sites near villages are generally better than others, as they are spontaneously protected by the villagers. Therefore, after long-term secondary succession, the community degradation is not obvious. Combined with semivariance analysis, it can be recognized that human activities in Nanxiong red beds soft rock area are related to topography, the soil $\mathrm{P}$ and $\mathrm{K}$ nutrients distribution in low hill basin. The interference degree on land and vegetation is different, which leads to vegetation degradation phenomenon with enhanced drought, and the landscape is similar to red beds desert.

\section{Correlation Analysis of Soil P, K and Terrain Factors}

It can be seen from Table 4 that soil $\mathrm{P}$ and $\mathrm{K}$ nutrients have an extremely significant positive correlation with terrain factor elevation and aspect, among which soil AK has a very significant positive correlation with elevation $(P<0.01)$ with a correlation coefficient of 0.901 . There was a significant positive correlation between soil AP and elevation $(P<0.01)$ with a correlation coefficient of 0.715 . The soil $\mathrm{P}$ and $\mathrm{K}$ nutrients were negatively correlated with slope gradient, and soil TP was significantly negatively correlated with slope $(P<0.01)$ with a correlation coefficient of -0.148. It can be concluded that terrain factors significantly affect the spatial distribution of soil $\mathrm{P}$ and $\mathrm{K}$. Elevation is the most influential terrain fator, with a correlation coefficient of 0.901 . The results showed that the topography of the study area was higher in the Southeast and lower in the Northwest. The change of land use types with altitude was forestland $>$ farmland $>$ grassland $>$ bare land. Also, with the decrease of altitude, both the plant quantity, and organic matter content decrease, which further lead to the decrease of soil $\mathrm{P}$ and $\mathrm{K}$ nutrient content. However, the content of TP and TK was higher in the farmland with lower altitudes, which was consistent with the results of Wang et al. [36].

Soil $\mathrm{P}$ and $\mathrm{K}$ nutrients were positively correlated with slope aspect, and soil TP, AP, AK had significant positive correlation with slope aspect, indicating that the more sunny the soil is, the higher the content of soil $\mathrm{P}$ and $\mathrm{K}$. That is because under the condition of sufficient sunlight on the sunny slope, the heterogeneity of light source was stronger, and the temperature change of forest land was more severe than that of the shady slope, which affected the microbial activity of forest soil. Therefore, the decomposition and oxidation rates of organic matter, phosphorus and potassium in sunny slope soil are relatively slow, which is conducive to the accumulation of phosphorus and potassium. The soil $\mathrm{P}, \mathrm{K}$ nutrients and slope showed a positive correlation, and soil TP, AP and slope showed a significant negative correlation. The reason is that the larger the slope, the more serious soil and water loss. Therefore, in the larger slope area, the soil $\mathrm{P}$ and $\mathrm{K}$ nutrient content are relatively low, and the soil $\mathrm{P}$ has the characteristics of 
Table 4. Correlation analysis between soil P, K and topographic factors.

\begin{tabular}{|c|c|c|c|c|c|c|c|}
\hline Soil nutrients & $\begin{array}{c}\mathrm{TP} \\
\left(\mathrm{g} \mathrm{kg}^{-1}\right)\end{array}$ & $\begin{array}{c}\mathrm{TK} \\
\left(\mathrm{g} \mathrm{kg}^{-1}\right)\end{array}$ & $\begin{array}{c}\text { AP } \\
\left(\mathrm{mg} \mathrm{kg}^{-1}\right)\end{array}$ & $\begin{array}{c}\mathrm{AK} \\
\left(\mathrm{mg} \mathrm{kg}^{-1}\right)\end{array}$ & Elevation (m) & Aspect & Slope $\left(^{\circ}\right)$ \\
\hline $\mathrm{TP}\left(\mathrm{g} \mathrm{kg}^{-1}\right)$ & 1 & & & & & & \\
\hline $\mathrm{TK}\left(\mathrm{g} \mathrm{kg}^{-1}\right)$ & $0.630^{* *}$ & 1 & & & & & \\
\hline $\mathrm{AP}\left(\mathrm{mg} \mathrm{kg}^{-1}\right)$ & $0.661^{* *}$ & $0.679^{* *}$ & 1 & & & & \\
\hline $\mathrm{AK}\left(\mathrm{mg} \mathrm{kg}{ }^{-1}\right)$ & $0.652^{* *}$ & $0.733^{* *}$ & $0.828^{* *}$ & 1 & & & \\
\hline Elevation (m) & $0.578^{* *}$ & $0.661^{* *}$ & $0.715^{* *}$ & $0.901^{* *}$ & 1 & & \\
\hline Aspect & $0.229^{* *}$ & $0.140^{* *}$ & $0.285^{* *}$ & $0.260^{* *}$ & $0.165^{*}$ & 1 & \\
\hline Slope $\left(^{\circ}\right)$ & $-0.148^{*}$ & -0.48 & -0.107 & -0.087 & -0.076 & -0.057 & 1 \\
\hline
\end{tabular}

*The correlation was significant at the 0.05 level.

$* *$ The correlation was significant at the 0.01 level.

easy loss. As a result, the correlation between soil $\mathrm{P}$ and the slope is more significant $(P<0.05)$, and Liu et al. [7] obtained similar results when studying the spatial heterogeneity of soil phosphorus in the loess plateau in China.

\section{Conclusion}

In this study, we selected an ecologically fragile environment of red beds in southern China as the study area to study the spatial variability of soil $\mathrm{P}$ and $\mathrm{K}$ nutrients. The results showed that there was a strong spatial correlation between soil $\mathrm{P}$ and $\mathrm{K}$ contents in red beds, and the spatial variation was mainly affected by structural factors. Soil AK content had a moderate spatial correlation. The content of soil TP, TK, AP, AK in the southeast of the study area were higher than that in other areas. By analyzing the correlation between terrain environmental factors and soil $\mathrm{P}$ and $\mathrm{K}$ nutrients, it can be concluded that the elevation and slope aspect have more significant effects on soil $\mathrm{P}$ and $\mathrm{K}$ nutrients than other factors. At present, the management of red beds' fragile ecological environment is a complex comprehensive project, which requires collaborations of forestry, agriculture, water conservancy and other fields. However, for a long time, due to the lack of indepth theoretical research support for the red bed desert control technical measures, the process of the red beds' ecological environment governance is slow, resulting in rising red beds desertification, and soil loss problems. The results of this study are expected to provide practical guidance and scientific basis for the protection of red beds' fragile ecological environment and the restoration and reconstruction of the red bed desert.

\section{Acknowledgements}

This work was supported by the National Natural Science Foundation of China (No.51779279,
No.51822908 and No.41771008), the Fundamental Research Funds for the Central Universities of China (No.20lgjc04, 20lgpy158 and 20lgpy157) and the Project funded by China Postdoctoral Science Foundation (No.2020M672941).

\section{Conflict of Interest}

The authors declare no conflict of interest.

\section{References}

1. FITTER A.H., GILLIGAN C.A., HOLLINGWORTH K., KLECZKOWSKI A., TWYMAN R.M., PITCHFORD J.W. Biodiversity and ecosystem function in soil. Functional Ecology, 19, 369, 2005.

2. MA J., LI L.H., GUO L.P., BAI L., ZHANG J.R., CHEN Z.H., AHMAD S. Variation in soil nutrients in grasslands along the Kunes River in Xinjiang, China. Chemistry and Ecology, 31 (2), 111, 2015.

3. TANG X.L., XIA M.P., GUAN F.Y., FAN S.H. Spatial distribution of soil nitrogen, phosphorus and potassium stocks in moso bamboo forests in subtropical China. Forests, 7 (267), 1, 2016.

4. ANNANBI M., RACLOT D., BAHRI H., BAILLY J.S., GOMEZ C., BISSONNAIS Y.L. Spatial variability of soil aggregate stability at the scale of an agricultural region in tunisia. Catena, 153, 157, 2017.

5. GHORBANI A., MOGHADDAM S.M., MAJD K.H., DADGAR N. Spatial variation analysis of soil properties using spatial statistics: a case study in the region of Sabalan mountain, Iran. Eco Mont-journal on Protected Mountain Areas Research, 1 (1), 70, 2018.

6. YE L.P., TAN W.F., FANG L.C., JI L.L., HUANG D. Spatial analysis of soil aggregate stability in a small catchment of the Loess Plateau, China: I. Spatial variability. Soil \& Tillage Research, 179, 71, 2018.

7. LIU Z.P., SHAO M.A., WANG Y.Q. Spatial patterns of soil total nitrogen and soil total phosphorus across the entire Loess Plateau region of China. Geoderma, 197-198, 67, 2013.

8. DAI W., LI Y.H., FU W.J., JIANG P.K., ZHAO K.L., LI Y.F., PENTTINEN P. Spatial variability of soil nutrient 
$\mathrm{s}$ in forest areas: A case study from subtropical China. Journal of Plant Nutrition and Soil Science, 181, 827, 2018.

9. SHENG M.Y., XIONG K.N., WANG L.J., LI X.N., LI R., TIAN X.J. Response of soil physical and chemical properties to rocky desertification succession in south China karst. Carbonates \& Evaporites, 33, 15, 2018.

10. JIANG F., WU X.H., XIANG W.H., FANG X., ZENG Y.L., OUYANG S., LEI P.F., DENG X.W., PENG C.H. Spatial variations in soil organic carbon, nitrogen and phosphorus concentrations related to stand characteristics in subtropical areas. Plant Soil, 413, 289, 2017.

11. BOGUNOVIC I., TREVISANI S., SEPUT M., JUZBASIC D, DURDEVIC B. Short-range and regional spatial variability of soil chemical properties in an agroecosystem in eastern Croatia. Catena, 154, 50, 2017.

12. YAO X., YU K.Y., DENG Y.B., LIU J., LAI Z.J. Spatial variability of soil organic carbon and total nitrogen in the hilly red soil region of southern china. Journal of Forestry Research, 31 (6), 2385, 2020.

13. JIANG H.L., LIU G.S., WANG R., SHI H.Z., HU H.C. Spatial variability of soil total nutrients in a tobacco plantation field in central China. Communications in Soil Science and Plant Analysis, 43 (14), 1883, 2012.

14. BAO Z., WU W.Y., LIU H.L., YIN S.Y., CHEN H.H. Geostatistical analyses of spatial distribution and origin of soil nutrients in long-term wastewater-irrigated area in Beijing, China. Acta Agriculturae Scandinavica, Section B-Soil \& Plant Science, 64 (3), 235, 2014.

15. VASU D., SINGH S.K., SAHU N., TIWARYA P., CHANDRANA P., DURAISAMI V.P., RAMAMURTHY V., LALITHA M., KALAISELVI B. Assessment of spatial variability of soil properties using geospatial techniques for farm level nutrient management. Soil \& Tillage Research, 169, 25, 2017.

16. BEHERA S.K., MATHUR R.K., SHUKLA A.K., SURESH K., PRAKASH C. Spatial variability of soil properties and delineation of soil management zones of oil palm plantations grown in a hot and humid tropical region of southern India. Catena, 165, 251, 2018

17. GWAK Y., KIM S. Factors affecting soil moisture spatial variability for a humid forest hillslope. Hydrological Processes, 31, 431, 2017.

18. MOTAGGHIAN H.R., MOHAMMADI J. Statistical and geostatistical appraisal of spatial variability of aggregate stability and aggregate-associated organic carbon content on a catchment scale in a semi-arid region, central Iran. Desert, 17, 27, 2012.

19. YOU W.Z., ZENG D.H., LIU M.G., YUN L.L., YE Y.H., ZHANG Y. Spatial and temporal variations of soil moisture in three in three types of agroforestry boundaries in the Loess Plateau, China. Journal of Forestry Research, 21 (4), 415, 2010.

20. LIU Z.P., SHAO M.A., WANG Y.Q. Scale-dependent correlations between soil properties and environmental factors across the loess plateau of china. Soil Research, 51 (2), 112, 2013.

21. ZHANG Z.M., HUANG X.F., ZHOU Y.C. Spatial heterogeneity of soil organic carbon in a karst region under different land use patterns. Ecosphere, 11 (3), 1, 2020.

22. YANG R., SU Y.Z., GAN Y.T., DU M.W., WANG M. Fieldscale spatial distribution characteristics of soil nutrients in a newly reclaimed sandy cropland in the Hexi Corridor of
Northwest China. Environmental Earth Sciences, 70 (7), 2987, 2013.

23. CAO C.G., JIANG S.Y., YING Z., ZHANG F.X., HAN X.S. Spatial variability of soil nutrients and microbiological properties after the establishment of leguminous shrub Caragana microphylla Lam. plantation on sand dune in the Horqin Sandy Land of Northeast China. Ecological Engineering, 37 (10), 1467, 2011.

24. ZHU X.M., HAN B.J., ZHAO J. Spatial and temporal variability of soil nutrients in the black soil area of northeast China. Journal of Food Agriculture and Environment, 11 (2):1386, 2013.

25. YAN L.B., HE R.X., KAŠANIN-GRUBIN M., LUO G.S., PENG H., QIU J.X. The dynamic change of vegetation cover and associated driving forces in Nanxiong Basin, China. Sustainability, 9 (3), 1, 2017.

26. YAN L., PENG H., ZHANG S.Y., ZHANG R.X., KAŠANIN-GRUBIN M., LIN K.R., TU X.J. The spatial patterns of Red Beds and Danxia Landforms: Implication for the formation factors-China. Scientific Reports, 9, 1, 2019.

27. PENG H., YAN L.B., CHEN Z., SIMONSON S., LUO G.S. A preliminary study of desertification in red beds in the humid region of Southern China. Acta Geographica Sinica, 70, 1699, 2015.

28. YAN P., PENG H., YAN L.B., LIN K.R. Spatial variability of soil physical properties based on GIS and geo-statistical methods in Nanxiong Basin, China. Polish Journal of Environmental Studies, 28, 2961, 2019.

29. 29. MURPHY J., RILEY J.P. A modified single solution method for the determination of phosphate in natural water. Analytica Chimica Acta. 27, 31, 1962.

30. ZHANG X.Y., SUI Y.Y., ZHANG X.D., MENG K., HERBERT. Spatial variability of nutrient properties in black soil of northeast China. Pedosphere, 17 (1), 19, 2007.

31. GOOVAERTS P., JOURNEL A.G. Integrating soil map information in modeling the spatial variation of continuous soil properties. European Journal of Soil Science, 46, 397, 1995.

32. HAN F.G., ZHENG J.Y., HU W., DU F., ZHANG X.C. Spatial variability and distribution of soil nutrients in a catchment of the Loess Plateau in China. Acta Agriculturae Scandinavica, 60 (1), 48, 2010.

33. CAMBARDELLA C., MOORMAN T.B., NOVAK J.M., PARKIN T.B., KARLEN D.L., TURCO R.F., KONOPKA A.E. Field-scale variability of soil properties in central Iowa soils. Soil Science Society of America Journal, 58, 1501, 1994.

34. FU W.J., ZHAO K., ZHANG C.S., TUNNEY H. Using Moran's I and geostatistics to identify spatial patterns of soil nutrients in two different long-term phosphorusapplication plots. Journal of Plant Nutrition and Soil Science, 174, 785, 2011.

35. TU J., XIA Z.G. Examining spatially varying relationships between land use and water quality using geographically weighted regression I: Model design and evaluation. Science of The Total Environment, 407, 358, 2008.

36. WANG Y.Q., ZHANG X.C., HUANG C.Q. Spatial variability of soil total nitrogen and soil total phosphorus under different land uses in a small watershed on the Loess Plateau, China. Geoderma, 150, 141, 2009. 